\title{
Dravet Syndrome
}

National Cancer Institute

\section{Source}

National Cancer Institute. Dravet Syndrome. NCI Thesaurus. Code C116573.

A severe form of epilepsy that presents in early childhood and is characterized by frequent, prolonged febrile or myoclonic seizures that may progress to status epilepticus and poor development of language, motor, and socialization skills. 